\title{
Conservation and solar energy in residential and commercial buildings
}

\section{The northern industrialized USA}

\author{
Mark R. Berg and Mark L. Hassett
}

\begin{abstract}
This recently completed study discusses the potential of conservation and solar energy in Michigan. While much of the quantitative analysis is specific to Michigan, the problems and opportunities discussed are largely generic to the northern industrial states in the USA. Technical estimates of energy savings potential are combined with economic analyses and market penetration considerations to provide an overall picture of the potential for conservation and solar energy. Barriers to market penetration are used as a basis for identifying a wide range of economic, informational, and institutional policy options for consideration by government and private sector decisionmakers.
\end{abstract}

Keywords: Conservation; Solar energy; USA

The authors are with the Energy Policy Group, Center for Research on the Utilization of Scientific Knowledge, Institute for Social Research, The University of Michigan, Ann Arbor, MI, USA

The authors are indebted to their former colleague Paul $\mathrm{H}$. Ray for his insights and collaborative efforts which were integral to the project reported in this article.
The effects of the economic recession in the USA have been especially hard felt in the northern industrialized region of the country. In those states heavily reliant on car or related manufacturing, unemployment has ranged from 1.5 to 2.5 times the national average. In urban areas such as Detroit and Flint, Michigan, the unemployment rate has at times been as high as three times the national average. For many individuals the only response has been to leave the northern states in search of work. For those who have remained, rising energy prices have eaten away at already dwindling unemployment benefits. Severely depressed manufacturing-based economies, high unemployment and large social relief burdens place the northern states in a seriously disadvantaged position to deal with the impacts of energy price increases.

Three factors underscore the urgent nature of the situation:

There is general agreement among both industry representatives and independent researchers that the price of natural gas (the heating fuel that is most used in the northern states) will continue to rise at a rate well above that of general inflation over the next five to ten years. These price increases will bite severely into the pockets of both residential and commercial energy users already burdened with the depressed economies and high unemployment of many northern industrial states.

- Taking Michigan as an example, it is estimated that over $\$ 8.2$ billion left the state in 1981 to pay for all forms of imported energy. Most of the other northern states face a similar predicament. While some of this money returns in other forms, a sound long-term strategy would try to stem some of this flow and hold it within the state where it can stimulate rather than drain the economy. It is important to recognize that energy problems in the northern industrial states can, in part, be transformed into much needed economic development opportunities. These opportunities include the establishment of new 
industries, adaptive reuse of manufacturing facilities, and the creation of jobs in the energy services area.

- The impacts of sharply rising fuel bills and supply uncertainties are hardest felt by the segments of the population least able to readjust - the poor and the elderly. Frequently living in poorly insulated, older housing, these individuals often have limited resources to invest in energy conservation. The sharply rising prices expected in the next ten years will require that measures be taken to deal effectively with this social equity problem. ${ }^{1}$

\section{The potential impact of conservation and solar energy}

This article summarizes a study carried out at The University of Michigan in 1981 and 1982, addressing a number of these energy related problems and opportunities. ${ }^{2,3}$ The work was commissioned by the Energy Administration of the Michigan Department of Commerce and had three main objectives:

- to examine the range of conservation and solar energy technologies (space heating, water heating, and lighting) which could be cost-effectively employed in residential and commercial buildings in Michigan's climatic range;

- to estimate the potential aggregate energy savings within the state if those technologies were adopted in an aggressive manner during the next two decades;

- to identify major barriers to the widespread adoption of conservation and solar energy technologies, and to identify a range of options to deal with the most serious of these barriers.

The study was designed to provide background data and policy analysis for state and local government officials with responsibility for conservation and solar energy programmes. Another audience was the large number of individuals and private sector organizations interested in solar economics and barriers to market penetration.

\section{Methodology}

'Mark R. Berg, Paul H. Ray and Mark A. Boroush, Jobs and Energy in Michigan: The Next Twenty Years, Institute for Social Research, University of Micr:gan, Ann Arbor, MI, 1981.

${ }^{2}$ Mark R. Berg, Paul H. Ray and Mark L. Hassett. The Use of Conservation and Solar Energy in Michigan: An assessment of opportunities and barriers for residential and commercial buildings, Center for $\mathrm{Re}$ search on Utilization of Scientific Knowledge, Institute for Social Research, University of Michigan, Ann Arbor, MI, February 1982.

${ }^{3}$ Mark A. Boroush, Mark R. Berg and Dennis L. Meany, Solar Applications in Michigan's Industrial Sector: An assessment of opportunities and barriers, Center for Research on Utilization of Scientific Knowledge, Institute for Social Research, University of Michigan, Ann Arbor, MI, February 1982.
The results and approach of this study should be of considerable interest in states and local governments outside Michigan and in countries outside the USA. Many of its results, policy considerations, and analysis of barriers are likely to be directly applicable in other areas, and especially so in other cold climate states heavily dependent on natural gas.

Of particular appeal from a strategic and political perspective is the study's quantitative estimate of the potential aggregate contribution of conservation and solar to the state's long-term energy needs. Estimates such as these can provide policymakers with a stronger basis upon which to argue for the funding allocations and programmes needed to fully achieve long-run energy goals. The basic methodological approach entailed the following.

A wide range of baseline data concerning energy consumption in residential and commercial sectors were collected.

- A set of standard systems which could yield representative energy savings were analysed, based on a careful review of state-of-the-art conservation and solar technology. 
- The various technical configurations were combined with a housing stock and land use analysis to define the maximum energy savings achievable for individual units and for the state as a whole.

- An economic analysis was prepared to test the cost-effectiveness of solar systems having similar technical configurations but different installation factors. Professional retrofit, do-it-yourself, and new home systems were evaluated with regard to other variables such as system efficiency, level of tax credits, and loan interest rates.

- An analysis of the innovation and adoption process as it applies to solar equipment was used to assess potential barriers which might inhibit solar energy in the market place.

- A range of policy options for the state, needed to remove or accommodate the most significant barriers to conservation and solar energy, were identified.

The methods and data used to estimate aggregate conservation and solar potential at the state level provide a relatively simple way of developing comparable analysis at the local level or within other states. The study has already been used as a basis for projecting the potential for conservation and solar technologies within several Michigan counties. This approach, in which the state level results are steppeddown to the local level, has proved far simpler and less data intensive than other methods typically used for local or regional analysis.

\section{Revising the myth about solar}

There is a widely accepted myth that solar cannot work in the Northern USA because of low insolation during the heating season. Indeed, it is true that a northern state such as Michigan receives less radiation than its southern neighbours, such as Georgia. But the longer and more intense heating season of the North enables solar equipment to convert the available insolation into useful heat during more of the year, and all other things being equal, at a lower cost per Btu. During the three coldest months of winter, back-up systems are required in most existing buildings in the North to complement an economically efficient solar configuration. However, during the early and late months of the long northern heating season, solar can provide the vast majority of heat requirements in well insulated structures.

Based on a detailed analysis of energy performance for eight major residential and commercial building types in Michigan, the study concludes that within two to three decades solar energy could provide $25-30 \%$ of the state's building energy needs. Other alternative energy sources, not specifically considered in this study (such as wood, biomass, wind, and hydropower), could be expected to make the total solar contribution even higher. While there are important market penetration barriers which may delay or prevent achieving these gains, solar contributions of this magnitude could provide Michigan and other northern states with an important buffer against the rising costs and supply vulnerabilities of conventional fuels. Furthermore, the findings relating to conservation are even more promising in this regard than those relating to solar.

\section{The crucial role of conservation}

Energy conservation in Michigan's residential and commercial buildings could provide as much as 3.5 times the conventional fuel savings that 


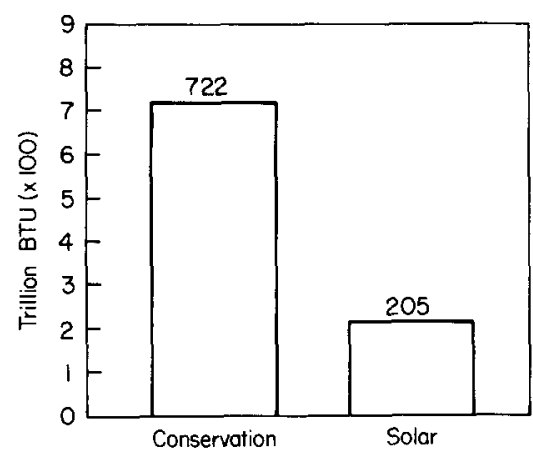

Figure 1. Potential savings in residential and commercial buildings.

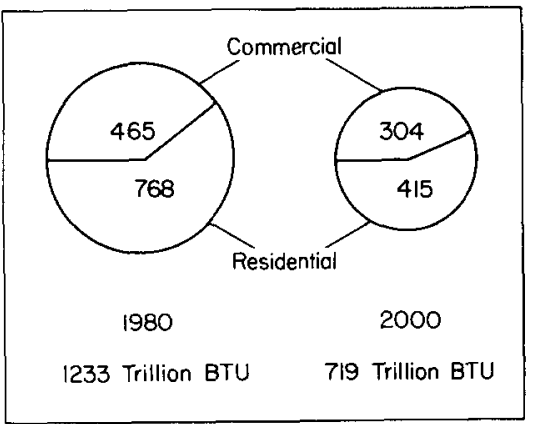

Figure 2. Potential reduction in energy demand.

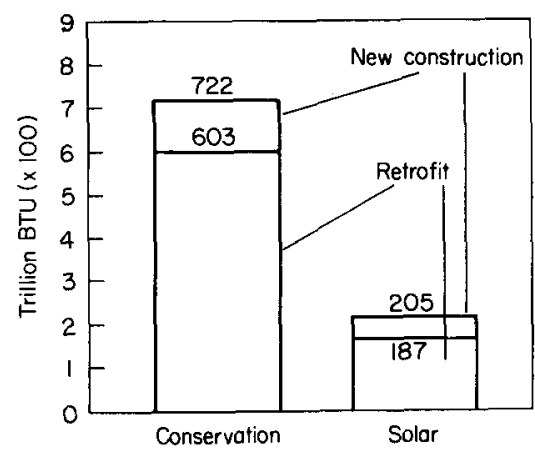

Figure 3. Retrofit versus new construction savings. could be provided by solar: 722 trillion Btu from conservation as opposed to 205 trillion Btu from solar (see Figure 1). It is, in fact, only because of these conservation gains that solar energy can provide such a significant share of building energy. Solar energy may be successful in Michigan, but conservation will be even more valuable.

\section{Potential energy savings from conservation and solar}

Even with a projected economic growth in Michigan of $25-30 \%$ over the next 20 years (about $1.3 \%$ per year), the residential sector primary energy use (including solar) could decline by almost $50 \%$ from 768 trillion Btu in 1980 to 415 trillion Btu in 2000 (see Figure 2). Average savings per residential dwelling are about $60 \%$. The comparable commercial sector projections are for a $35 \%$ decline, from 465 trillion Btu in 1980 to 304 trillion Btu in 2000. Overall, the building sector's energy demand could decline by over $40 \%$ due to conservation measures.

The detailed quantitative findings permit other useful comparisons in terms of relative energy savings from retrofits versus new construction, and residential versus commercial markets. Comparisons such as these, presented below, provide a basis for making informed marketing and programme development choices.

While conservation and solar are more efficiently installed and yield more savings in new buildings than in those which are old, the essential fact is that the retrofit market in any year is some 40 times larger than the new building market. Thus, over the next 20 years, the total conservation retrofit potential in terms of Btu saved is over 5 times greater than the new construction potential (603 trillion Btu rather than 119 trillion Btu, as shown in Figure 3). Total solar retrofit potential savings are over 11 times greater than the new construction solar potential (187 trillion Btu instead of 17 trillion Btu).

The detailed technical and quantitative assumptions in the original study's appendix allow readers to examine the sensitivity of these results to alternative assumptions. ${ }^{4}$ In general, however, the robustness of the findings leaves little doubt that there are much greater energy savings to be obtained from conservation than from solar, from retrofit than from new construction, and from the residential sector than from the commercial sector. While energy savings from all areas are of value, from a policy and marketing standpoint it is important to note that the following three areas alone contributed almost $80 \%$ of the total potential energy savings identified in the analysis:

- retrofit residential conservation (378 trillion Btu);

- retrofit commercial conservation (224 trillion Btu);

- retrofit residential solar (126 trillion Btu).

These areas should be at the core of government policies to reduce energy vulnerability and the outflow of energy dollars from the northern states.

\section{Residential solar economics}

An analysis was conducted on the economics of passive solar in various Michigan locations. Passive systems (and the more simple active systems) are felt to currently hold the most potential for residential 
applications on the basis of cost versus potential space heat savings. However, at today's energy prices, even with relatively cost-effective solar systems, a cost-conscious homeowner will insulate before installing solar. But by the late 1980 s, rising natural gas prices should make solar an attractive next step. Solar adoptions are held down somewhat by low natural gas prices in the northern states, but as relative prices rise, the cold climate (and high heating bills) will together accelerate the penetration of both conservation and solar.

To explore these issues of relative cost in a quantitative manner, an analysis was conducted of the economics of passive solar in various Michigan locations. The analysis utilized computer based modelling of cash flow to determine, first, the economic factors (eg interest rates, fuel prices, tax benefits etc) influencing the return on investment of a solar installation, and, second, the sensitivity of these factors in relation to the uncertainty associated with each variable. ${ }^{5}$

A hypothetical passive solar system was designed to incorporate a sunspace, increased south facing glazing, and thermosyphon air panels. The costs for the system were structured into three possible installation situations: (1) a do-it-yourself retrofit, (2) a professional retrofit, and (3) a new home option. Some general findings of the analysis are presented below.

- Natural gas prices will greatly influence economic performance. The higher natural gas prices rise, the better the outlook for solar energy.

- Solar can be cost-effective in most of Michigan, but the longer, more intense heating season of the northern part of the state will enable a well designed installation to extract more energy per year in the north than equivalent systems in Southern Michigan.

- The do-it-yourself system has very good economic performance due to low initial costs, but a poorly engineered or installed system will quickly reverse economic performance.

- A variation in the annual fraction of space heat provided by the standard system (as measured by the Solar Savings Fraction or SSF) will influence economic performance. This can be due to factors such as poor engineering, careless siting, or reduced insolation. If natural gas prices rise more slowly than expected, a more efficient system will help to insure a good return on the solar investments.

\section{The issue of market penetration}

It should be stressed that the potential energy savings identified by this study reflect the potential market for conservation and solar technologies. Actual market penetration will be considerably smaller than the upper limit defined by market potential. While the economic analyses of this study (and numerous others) suggest that potential market penetration could be substantial, actual levels of market penetration will depend on far more than just economics. Unfortunately, our knowledge of the factors affecting the adoption of all innovations, not just solar, is such that any estimates of market penetration should be viewed with considerable scepticism. We are faced with a host of uncertainties both

${ }^{5}$ Booz-Allen and Hamilton, Inc, RSVP/2: Residential Solar Viability Program, Users Manual, $\mathrm{H}-2493,7054-014$, available from Solar Energy Research Institute, Golden, CO, SERI/SP-751-685, 1975. in our theories and in our knowledge about future conditions, such as energy prices and supply levels, government energy policies, the development pattern of the solar and conservation industries, consumer acceptance, and changes in related financial institutions. 
Rather than trying to predict levels of market penetration in the face of these many uncertainties (as others have done, for example Booz-Allen ${ }^{6}$ ), the study attempted a better definition of the uncertainties and ways in which they may be resolved over the years ahead. An eclectic approach was used in which three alternative perspectives on the adoption of innovations were used to identify major uncertainties and barriers affecting conservation and solar market penetration: characteristics of the innovation, characteristics of the adopters, and steps in the innovation adoption process.

\section{Characteristics of successful innovations}

Are there characteristics of conservation and solar technologies which make them more or less likely to be quickly accepted by consumers? The innovation literature identifies a number of criteria along which conservation and solar can be evaluated. ${ }^{7,8}$

- Does the technology offer a relative advantage in solving a problem of relevance to the adopter?

- Is it compatible and credible within the context of previous norms, lifestyles, and beliefs?

- Can the innovation be easily observed and communicated as feasible, or does it appear to be overly complex, unreliable, and uncertain?

- Can it be adopted on a trial basis or on a step by step basis which is easily reversible if the innovation does not prove desirable?

- Are there financial or social status risks associated with adoption of the innovation?

Note that economic advantages are of some importance in this list, but very frequently other factors dominate the adoption decision and the rate of diffusion. This reflects the fact that technological change is often great and discontinuous with the potential for affecting lifestyles and social relationships. This is especially true of solar and of many conservation options beyond the low-cost/no-cost variety. In general, conservation looks 'better' when evaluated along these criteria than does solar. However, innovative approaches to solar marketing and financing (such as lease-purchase agreements) may significantly help solar market penetration by minimizing the more serious risks of adoption.

${ }^{6}$ Booz-Allen and Hamilton, Inc, Passive Economies and Market Analysis Model, Bethesda, MD, 1980.

${ }^{7}$ National Institute of Mental Health (NIMH), Planning for Creative Change in Mental Health Services: A Distillation of Principles on Research Utilization, (Volumes I and II), NIMH, Washington, DC; Department of Health, Education, and Welfare (DHEW) and (NIMH), DHEW Publication No (HSM) 73-9148, 1971.

${ }^{8}$ Duncan G. LaBay and Thomas C. Kinnear, Exploring the Consumer Decision Process in the Adoption of Solar Energy Systems, Working Paper No 257, Graduate School of Business Administration, University of Michigan, 1981.

${ }^{9}$ Everett M. Rogers, Diffusion of Innovations, Free Press, New York, NY, 1962.

\section{The adopters of innovations}

Another way to explore conservation and solar market penetration is in terms of the social psychology of the adopter in the innovation process. Rogers (1962) categorized consumers into five categories of 'innovativeness' along a rough continuum of time: innovators, early adopters, early majority, later majority, and laggards. ${ }^{9}$ These groups tend to differ from one another in important ways. For example, innovators (the first $2-3 \%$ ) tend to be different types of people from the early adopters of an innovation (the next 10-15\%). The innovators tend to be more technically oriented, higher in income and education, more prone to be hobbyists, enthusiasts and risk-takers, and less likely to be local opinion leaders than are the next wave of adopters. The early adopters are more prone to be the kind of local opinion leaders who lead the popularization of an innovation into widespread adoption. They are often emulated by other consumers who look to them for advice, interpreta- 
tion, status and product imagery at the time of adopting a durable good like solar (as is the case with automobiles, clothing, housing, and other lifestyle goods). They are more apt to be concerned with lifestyle issues and the consumption of goods than with sophisticated new hardware, or with hobbyist/enthusiast innovations.

Essential to our understanding of the solar market is the fact that solar now seems to be at the transition point from the innovators stage to that of the early adopters. If solar makes this transition, to between $10 \%$ and $20 \%$ of the potential adopters, its further success is highly probable. However, this is a transition to different types of consumers with different types of tastes and expectations, and different spending habits. This means that if solar is to achieve widespread success, it faces a significant change in the character of the solar market, and a change in the types of marketing appeals likely to be successful. Much of the experience gained during the early development of solar may prove to be a poor guide to what is coming in the immediate future. For example, the more complex types of active solar collectors and concentrators may not sell well beyond the enthusiasts' market. The early adopter market may be better penetrated by passive solar equipment such as greenhouses and sunspaces that add living space and amenity, quite apart from Btu savings. The latter suits the early adopter lifestyle. It is quite possible that different types of companies will be needed to serve this changing market, and they are most likely to be part of regional or national chains, selling standardized packages, or at least standard options in flexible packages. The most successful firms will probably have worked out various arrangements with lenders for home improvement loans and with local installers. Such companies are also more able to saturate the media with lifestyle oriented marketing campaigns, such as those already used to market many durable goods.

\section{Steps in the adoption process}

A third way to view market penetration is in terms of the steps or phases a consumer must go through in deciding to buy a new product. The innovation literature provides several descriptive models of the adoption process which are basically similar. ${ }^{10-13}$ The Rogers (1962) model, for example, consists of five stages: (1) awareness, (2) interest, (3) evaluation, (4) trial, and (5) adoption. Models such as these can be usefully applied to the adoption of conservation and solar, since market penetration barriers can occur at each stage. Our analysis identified eight steps as especially relevant to the purchase of conservation and solar services.

\footnotetext{
${ }^{10} /$ bid.

${ }^{11}$ Everett M. Rogers with F.F. Shoemaker, Communication of Innovations: A CrossCultural Approach, Free Press, New York, NY, 1976.

${ }^{12}$ Ronald G. Havelock with A. Guskin, Planning for Innovation Through Dissemination and Utilization of Knowledge, published by the Center for Research on Utilization of Scientific Knowledge (CRUSK), Institute for Social Research (ISR), University of Michigan, Ann Arbor, MI, 1969.

${ }^{13}$ Donald C. Pelz, Fred C. Munson and Linda $L$. Jenstrom, 'Dimensions of innovation', Journal of Technology Transfer, Vol 3, No 1, 1978, pp 35-49.
}

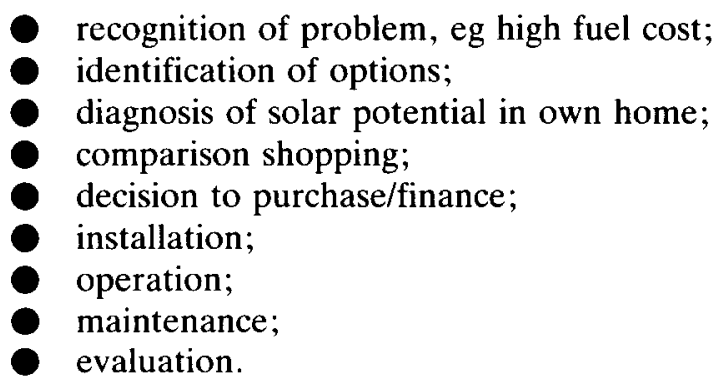

The problems faced by consumers at each of these stages imply specific barriers and means for their reduction that can be pursued by government officials and industry marketing strategists. The majority of 
these barriers involve the consumers' need for credible information and protection against inferior products and service. When combined with similar findings based on characteristics of successful innovations and adopters of innovations, a wide range of barriers and strategies were identified in this study. Indeed, they suggest that it cannot be taken for granted that solar, or all types of conservation, will achieve widespread consumer adoption, especially in the face of temporary softenings in fuel prices.

\section{Market barriers and policy development}

The major barriers to the spread of energy conservation and solar equipment tend to reflect three underlying aspects in the adoption of these innovations: economic, informational, and institutional. Economic barriers include factors such as unfavourable pricing, limited availability of capital and subsidies, inappropriate payback calculations, market failures, etc, making the product less viable than might be supposed from 'pure' economics. Informational barriers reflect not only poor information about new and rapidly changing conservation and solar technologies or economics, but also a lack of the expertise and skill needed for quality design and installation. Institutional barriers tend to reflect the general inertia and conservatism in social practices, rules, habits and power structures. These lead to various groups defending vested interests or conventional practices when faced with prospective changes that could result from the widespread adoption of conservation and solar. Overall, the study identified 22 different types of barrier. Many of the barriers involve a combination of economic, informational, and institutional factors, often making them difficult to diagnose and overcome. Table 1 has been arranged to show that barriers $1-4$ are primarily economic in nature, barriers 5-7 are primarily informational,

Table 1. Summary of barriers to conservation and solar energy.

Primarily economic barriers

(1) High initial cost of solar equipment and installation

(2) Limited financial incentives for timely adoption of conservation

(3) Problems in raising capital for solar and conservation purchases

(4) Lack of funds to promote conservation and solar

Primarily informational barriers

(5) Poor state of technical information on solar energy for consumers

(6) Limited consumer information on conservation products, behaviours, and programmes

(7) Conflicting information disseminated on conservation and solar by groups with different vested interests

Primarily institutional barriers

(8) Local government regulations and policies unfavourable to conservation and solar

(9) Limited social reinforcements for behavioural change related to conservation and solar

(10) Conservatism in the building industry about solar and conservation

Mix of economic, informational, and institutional barriers

(11) The landlord-renter dilemma: who pays?

(12) The economic/equity dilemma for the elderly and poor

(13) Short-term and inappropriate investment criteria

(14) Limited ability of consumers to calculate cost-effectiveness of solar and conservation

(15) Inappropriate analysis of solar by economists using overly narrow economic criteria

(16) Opposition by energy industry interests (oil, gas, utilities) to conservation and solar

(17) Immaturity of solar industry, and poor quality control by some builders

(18) Lack of awareness about the negative macroeconomic effects due to the cost of out-of-state energy

(19) Limited and weak feedback to consumers on their use of energy and results of energy conservation measures

(20) Lender policies unfavourable to solar and conservation

(21) Inadequate consumer protection

(22) Limited mechanisms for disseminating information on solar and conservation 
barriers $8-10$ are primarily institutional, and barriers $11-22$ are various mixtures of the former three categories.

This categorization of barriers is useful because it indicates the types of considerations required when developing state government and private sector policies on conservation and solar. The reality of the situation is that few 'pure' policies will overcome many barriers. Such policies tend to be recommended by specialists and are often too narrow. Subsidies and related economic measures are likely to have the most impact because most barriers have at least some economic component, but they are by no means sufficient on their own. Passing new regulations and aiming at institutional discrimination against conservation and solar can affect some barriers, but also cannot stand alone. Putting out better information on conservation and solar can affect still other barriers in varying degrees, but most are tinged with further problematic aspects. Hence a variety of tools will be required to remove or weaken most of the barriers, because they have the kind of mixed character that is inherent in any major social change.

It is apparent that both the public and private sectors should be prepared for significant changes in the scale of demand for conservation and solar technologies, in the nature of the market and consumer needs, and in the types of problems and opportunities to be encountered during the next twenty years. For example, the timing and scale of programmes designed to deal with consumer information and finance requirements will need to be tied closely to the take-off in demand for conservation and solar that can be expected as the cost impacts of natural gas deregulation begin to take effect in the gas dependent northern states.

\section{Conclusions}

A major challenge in the years ahead will be knowing in which areas of the innovation process, and at what time periods, state (or local) intervention will be needed to encourage cost-effective use of conservation and solar energy. Responding to this challenge will require an effective capacity for monitoring and responding to energy related conditions, programmes and technologies, both at the state and national levels. Current indications from Washington suggest that in the USA the federal role in assisting states and local governments in such efforts is likely to be minimal. Consequently, the time is ripe to develop long-term, state and locally based initiatives which will address the use of conservation and solar technologies as part of plans for a more stable energy future. 